\title{
Analisis Penerapan Kesehatan Dan Keselamatan Kerja (K3) di Perusahaan Jasa Konstruksi Kota Payakumbuh
}

\author{
Ade Dwi Putra ${ }^{1}$, Elvi Syamsuir ${ }^{2}$, dan Fatma Ira Wahyuni ${ }^{3}$ \\ Program Studi Teknik Sipil, Sekolah Tinggi Teknologi Payakumbuh ${ }^{1,2,3}$ \\ email: elvisyamsuir246@gmail.com ${ }^{2}$ \\ DOI: http://dx.doi.org/10.31869/rtj.v4i1.2034
}

\begin{abstract}
Salah satu tujuan dari penerapan keselamatan dan kesehatan kerja (K3) adalah untuk mencegah terjadinya kecelakaan kerja itu sendiri. Pada pelaksanaan konstruksi dituntut untuk tidak terjadi atau meminimalkan kecelakaan kerja dengan salah satu caranya adalah dengan menerapkan Sistem Menajemen Keselamatan dan Kesehatan Kerja (SMK3) yang baik sesuai dengan peraturan yang berlaku. Telah dilakukan suatu penelitian analisis penerapan Kesehatan dan Keselamatan (K3) di perusahaan jasa konstruksi kota Payakumbuh. Hal ini bertujuan untuk mengetahui penerapan SMK3 pada setiap proyek konstruksi di kota Payakumbuh serta untuk mengetahui apakah kontraktor telah menerapkan SMK3 di perusahaannya. Metode yang digunakan adalah kuatitatif. Hasil menunjukkan bahwa $31 \%$ menggunakan program K3 dan 69\% belum menerapkannya. Penyebab beberapa perusahaan tidak bisa menerapkan SMK3 adalah perusahaan tidak mempunyai dana khusus untuk K3 di proyek. Selain itu, tenaga kerja yang tidak disiplin cendrung mengabaikan APD dalam pekerjaan dan tidak adanya tenaga ahli K3 di perusahaan. Perlu adanya pengawasan yang lebih pada setiap perusahan jasa kontruksi, pekerja kontruksi dalam penerapan K3 disetiap pekerja kontruksi terutama di Kota Payakumbuh.
\end{abstract}

Keywords: SMK3, Perusahaan Jasa Konstruksi

\section{PENDAHULUAN}

Pesatnya pertumbuhan pembangunan di Indonesia sebagai negara berkembang (pada saat ini menuju negara maju berdasarkan list yang dikeluarkan oleh Amerika Serikat (Kompas, 2020)) serta banyaknya usaha jasa konstruksi terutama pelaksana pembangunan atau kontraktor dalam melaksanakan pembangunan tentu melibatkan tenaga kerja dalam jumlah besar. Hal ini jelas perlu penanganan serius dan tersistem terhadap keselamatan dan kesehatan kerja karena menyangkut jiwa manusia yang bekerja pada pelaksanaan konstruksi. Hal ini disebabkan pelaksanaan konstruksi pada setiap item pekerjaan mengandung potensi resiko yang membahayakan pekerja tersebut. Indrawati, 2017 pada penelitiannya yang berjudul Pengaruh kesehatan dan keselamatan kerja pada kepuasan kerja dan komitmen organisasional mengatakan bahwa banyak organisasi yang mengklem bahwa pekerja mereka merupakan aset yang sangat berharga bagi organisasi tersebut. Hal ini tentu perlu didukung oleh perlindugan kesehatan, keselamatan kerja pekerja tersebut guna memaksimalkan kinerja pekerja tersebut terhadap suatu perusahaan atau organisasi. Penelitian tentang keselamatan SMK3
(Sistem Manajemen Keselamatan dan Kesehatan Kerja) telah banyak dilaporkan seperti pada penelitian Fitriana, 2017 menyatakan bahwa peneramatan SMK3 pada PT Ahmadaris selama kurun waktu 3 tahun termasuk dalam katagori baik berdasarkan kriteria Peraturan Pemerintah Nomor 50 Tahun 2012. Penelitian selanjutnya dilaporkan oleh Wahyuni,dkk 2018 menyebutkan penerapan SMK3 pada proyek pembangunan gedung rawat inap di salah satu Rumah Sakit di Bukittinggi kurang diterapkan. Keselamatan dan Kesehatan Kerja (K3) merupakan hak dasar bagi tenaga kerja dimana salah satu tujuan dari keselamatan dan kesehatan kerja adalah untuk mencegah terjadinya kecelakaan kerja (Prabowo, 2019). Baru-baru ini pada tahun 2020 Siahaan,dkk melakukan penelitian tentang penerapan sistem manajemen keselamatan dan kesehatan kerja (SMK 3) (studi kasus pada proyek preservasi dan pelebaran jalan kota takengon - sp. uning uwaq) guna untuk mengetahui penerapan SMK3 pada proyek tersebut. Hal lain yang mendasarinya adalah kepedulian sebahagian perusahan kontruksi terhadap K3 secara umum masih terabaikan, hal ini ditunjukkan dengan angka kecelakaa kerja yang masih tinggi dan tingkat kepedulian dunia usaha yang masih 
rendah terhadap $\mathrm{K} 3$.

Berdasarkan

kajian literatur serta masalah-masalah yang telah diuraikan sebelumnya, penulis melakukan suatu penelitian tentang Analisis penerapan Kesehatan dan Keselamatan (K3) di perusahaan jasa konstruksi kota Payakumbuh. Hal ini bertujuan untuk mengetahui penerapan SMK3 pada setiap proyek konstruksi di kota Payakumbuh serta untuk mengetahui apakah kontraktor telah menerapkan SMK3 di perusahaannya. Hasil ini diharapkan menjadi gambaran bagi setiap perusahan konstruksi yang berada di Kota Payakumbuh tentang penerapan K3 diperusahan mereka apakah sudah memenuhi standar yang ditetapkan oleh pemerinta berdasarkan atas Peraturan Menteri Pekerjaan Umum Nomor: 05/PRT/M/2014 tentang Pedoman SMK3 Konstruksi Bidang Pekerjaan Umum yang ditetapkan tanggal 22 April 2014 yang merupakan pengganti Peraturan Menteri Pekerjaan Umum Nomor 09/PRT/M/2008.

\section{METODE PENELITIAN}

Penelitian ini dilakukan di Kota Payakumbuh terhadap perusahaan jasa pelaksana konstruksi yang aktif terdaftar pada Lembaga Pengembangan Jasa Konstruksi Provinsi (LPJKP) Sumatera Barat untuk Kota
Payakumbuh dengan klasifikasi menengah dan kecil yang berjumlah 40 perusahaan. Data yang digunakan dalam penelitian ini adalah data primer dan data sekunder. Dari segi proses pelaksanaan pengumpulan data, dengan dokumentasi dan observasi. Pengisian kuisioner menggunaan istilah Ya dan Tidak. Kriteria pengisian kuisioner sebagai berikut : Pada Kolom 3 pelaksanaan SMK3 dilaksanakan di proyek, pada Kolom 4 pelaksanaan SMK3 tidak dilaksanakan di proyek. Penulis menjumlahkan responden yang memilih setiap pernyataan pada kolom. Tingkat penilaian Implementasi Sistem Manajemen Kesehatan dan Keelamatan Kerja (SMK3) akan dianalisa mengacu kepada PP RI No. 50 Tahun 2012:

$$
\text { a. } 0 \%-59 \% \text { : Tingkat Penilaian }
$$

Implementasi Kurang

$$
\text { b. } 60 \%-84 \% \text { : Tingkat Penilaian }
$$

Implementasi Baik

$$
\text { c. } 85 \%-100 \% \text { : Tingkat Penilaian }
$$

Implementasi Memuaskan

Variabel yang akan digunakan untuk menghimpun data Penerapan Sistem Keselamatan Dan Kesehatan Kerja (SMK3) pada proyek konstruksi di kota Payakumbuh mengacu kepada penelitian Sanora (2012)

\begin{tabular}{|c|c|c|}
\hline No. & Variabel & Simbol \\
\hline \multicolumn{3}{|c|}{ Program K3 (Perancanaan, Pelaksanaan, dan Pengawasan K3) } \\
\hline 1. & $\begin{array}{l}\text { Apakah perencanaan yang dibuat } \\
\text { mempertimbangkan identifikasi bahaya pada } \\
\text { proyek yang akan dilakukan }\end{array}$ & $\mathrm{X} 1$ \\
\hline 2. & $\begin{array}{c}\text { Apakah penetapan dan sasaran K3 dikonsultasikan } \\
\text { dengan tenaga ahli K3 }\end{array}$ & $\mathrm{X} 2$ \\
\hline 3. & Apakah perencanaan K3 terkoordinasi & X3 \\
\hline 4. & $\begin{array}{c}\text { Apakah pengurus menjelaskan peraturan } \\
\text { perundangan dan persyaratan lainnya kepada setiap } \\
\text { tenaga kerja }\end{array}$ & $\mathrm{X} 4$ \\
\hline 5. & $\begin{array}{c}\text { Apakah para pekerja menyadari akan pentingnya } \\
\text { K3 }\end{array}$ & X5 \\
\hline 6. & $\begin{array}{c}\text { Apakah catatan inpeksi, pengujian dan pemantauan } \\
\text { terpelihara dengan baik }\end{array}$ & X6 \\
\hline 7. & $\begin{array}{c}\text { Apakah tujuan dan sasaran K3 yang ditetapkan } \\
\text { ditinjau secara teratur }\end{array}$ & $\mathrm{X} 7$ \\
\hline 8. & $\begin{array}{c}\text { Apakah petugas K3 (safety Officer) selalu } \\
\text { meninjau lokasi kerja }\end{array}$ & $\mathrm{X} 8$ \\
\hline 9. & $\begin{array}{c}\text { Apakah pelaksanaan audit SMK3 dilakukan secara } \\
\text { berkala }\end{array}$ & X9 \\
\hline 10. & $\begin{array}{l}\text { Apakah perusahaan menggunakan indikator kinerja } \\
\text { yang dapat diukur sebagai dasar penilaian kinerja }\end{array}$ & X10 \\
\hline
\end{tabular}
yang dapat ditampilkan pada Tabel 1:

Tabel 1 Parameter Variabel Penelitian 


\begin{tabular}{|c|c|c|}
\hline & K3 & \\
\hline \multicolumn{3}{|c|}{ Proses Manajemen K3 ( Kebijakan, Prosedur Dan Pelatihan) } \\
\hline 11. & $\begin{array}{c}\text { Apakah pelaksanaan pada proyek telah } \\
\text { memprioritaskan K3 }\end{array}$ & $\mathrm{X} 11$ \\
\hline 12. & $\begin{array}{l}\text { Apakah perusahaan menempatkan organisasi K3 di } \\
\text { posisi yang dapat menentukan }\end{array}$ & $\mathrm{X} 12$ \\
\hline 13. & $\begin{array}{l}\text { Apakah perusahaan membuat ketentuan untuk } \\
\text { mengkomunikasikan informasi K3 secara efektif }\end{array}$ & $\mathrm{X} 13$ \\
\hline 14. & $\begin{array}{c}\text { Apakah Manajemen perusahaan pada proyek } \\
\text { bertanggung jawab atas kinerja K3 }\end{array}$ & X14 \\
\hline 15. & $\begin{array}{c}\text { Apakah pelaksanaan pada Proyek telah memiliki } \\
\text { operasi standar }\end{array}$ & $\mathrm{X} 15$ \\
\hline 16. & $\begin{array}{l}\text { Apakah tersedia prosedur untuk identifikasi standar } \\
\text { kompetensi kerja dan penerapannya melalui } \\
\text { pelatihan }\end{array}$ & $\mathrm{X} 16$ \\
\hline 17. & $\begin{array}{l}\text { Apakah para pekerja menyadari akan pentingnya } \\
\text { K3 }\end{array}$ & $\mathrm{X} 17$ \\
\hline 18. & $\begin{array}{c}\text { Apakah ada dilaksanakan pelatihan K3 di Proyek } \\
\text { pada saat awal proyek }\end{array}$ & $\mathrm{X} 18$ \\
\hline 19. & $\begin{array}{l}\text { Apakah ada dilaksanakan pelatihan k3 pada setiap } \\
\text { kegiatan tertentu yang memiliki resiko kecelakaan } \\
\text { cukup besar }\end{array}$ & X19 \\
\hline \multicolumn{3}{|c|}{ Sumber Daya K3 (Material, Peralatan, Pendanaan dan Staff K3) } \\
\hline 20. & $\begin{array}{c}\text { Apakah dilokasi proyek terdapat sign board K3, } \\
\text { yang berisi slogan-slogan yang mengingatkan akan } \\
\text { perlunya bekerja dengan selamat }\end{array}$ & $\mathrm{X} 20$ \\
\hline 21. & $\begin{array}{c}\text { Apakah dilokasi proyek tersedia dengan lengkap } \\
\text { helm sebagai alat pelindung kepala }\end{array}$ & $\mathrm{X} 21$ \\
\hline 22. & $\begin{array}{l}\text { Apakah di lokasi proyek tersedia dengan lengkap } \\
\text { sepatu lapangan sebagai alat pelindung kaki }\end{array}$ & $\mathrm{X} 22$ \\
\hline 23. & $\begin{array}{l}\text { Apakah di lokasi proyek tersedia dengan lengkap } \\
\text { sabuk pengaman pada pekerjaan di ketinggian }\end{array}$ & $\mathrm{X} 23$ \\
\hline 24. & $\begin{array}{l}\text { Apakah di lokasi proyek tersedia dengan lengkap } \\
\text { masker pada pekerjaan yang menggunakan gas } \\
\text { beracun atau bahan berbahaya lainnya. }\end{array}$ & $\mathrm{X} 24$ \\
\hline 25. & $\begin{array}{c}\text { Apakah di lokasi proyek tersedia dengan lengkap } \\
\text { Kacamata las (las goggle) tersedia pada pekerjaan } \\
\text { las }\end{array}$ & $\mathrm{X} 25$ \\
\hline 26. & $\begin{array}{c}\text { Apakah di lokasi proyek telah tersedia dengan } \\
\text { lengkap obat-obatan untuk P3K }\end{array}$ & $\mathrm{X} 26$ \\
\hline 27. & $\begin{array}{c}\text { Apakah di lokasi proyek telah tersedia tabung } \\
\text { pemadam kebakaran }\end{array}$ & X27 \\
\hline 28. & $\begin{array}{l}\text { Apakah di lokasi proyek telah tersedia penangkal } \\
\text { petir darurat }\end{array}$ & $\mathrm{X} 28$ \\
\hline 29. & $\begin{array}{c}\text { Apakah di lokasi proyek telah tersedia pagar } \\
\text { pengaman lokasi }\end{array}$ & X29 \\
\hline 30. & $\begin{array}{l}\text { Apakah di lokasi proyek telah tersedia dengan } \\
\text { lengkap rambu-rambu peringatan bahaya dari atas }\end{array}$ & X30 \\
\hline 31. & $\begin{array}{l}\text { Apakah di lokasi proyek telah tersedia dengan } \\
\text { lengkap rambu-rambu peringatan benturan kepala }\end{array}$ & X31 \\
\hline
\end{tabular}




\begin{tabular}{|c|c|c|}
\hline 32. & $\begin{array}{l}\text { Apakah di lokasi proyek telah tersedia dengan } \\
\text { lengkap rambu-rambu peringatan bahaya api/ } \\
\text { kebakaran }\end{array}$ & X32 \\
\hline 33. & $\begin{array}{l}\text { Apakah di lokasi proyek telah tersedia dengan } \\
\text { lengkap rambu-rambu petunjuk untuk melapor } \\
\text { (keluar-masuk proyek) }\end{array}$ & X33 \\
\hline 34. & $\begin{array}{l}\text { Apakah di lokasi proyek telah tersedia dengan } \\
\text { lengkap rambu-rambu larangan memasuki areal } \\
\text { tertentu }\end{array}$ & X34 \\
\hline 35. & $\begin{array}{c}\text { Apakah di lokasi proyek telah tersedia dengan } \\
\text { lengkap rambu-rambu peringatan untuk pemakaian } \\
\text { alat pengaman kerja }\end{array}$ & X35 \\
\hline 36. & $\begin{array}{c}\text { Apakah para pekerja dilindungi dengan asuransi } \\
\text { kecelakaan }\end{array}$ & X36 \\
\hline 37. & $\begin{array}{c}\text { Apakah pelaksana proyek memiliki anggaran yang } \\
\text { diperlukan di bidang K3 }\end{array}$ & X37 \\
\hline 38. & $\begin{array}{l}\text { Apakah para pekerja dilindungi dengan asuransi } \\
\text { kecelakaan }\end{array}$ & X38 \\
\hline 39. & $\begin{array}{c}\text { Apakah pelaksana proyek memiliki anggaran yang } \\
\text { diperlukan di bidang K3 }\end{array}$ & X39 \\
\hline 40. & $\begin{array}{c}\text { Apakah menetapkan personil yang jelas dalam } \\
\text { penanganan K3 }\end{array}$ & $\mathrm{X} 40$ \\
\hline
\end{tabular}

Responden penelitian terdiri dari 23 orang kontraktor yang terlibat dalam perusahaan jasa konstruksi di kota Payakumbuh. Beberapa karakteristik dari responden yaitu :

\section{a. Umur}

Usia dari responden dibagi menjadi 5 kelompok yaitu <35 tahun, 36-40 tahun, 41-45 tahun, 46-50 tahun dan >50 tahun, dari data kuisioner diperoleh kelompok responden seperti pada Gambar 1.

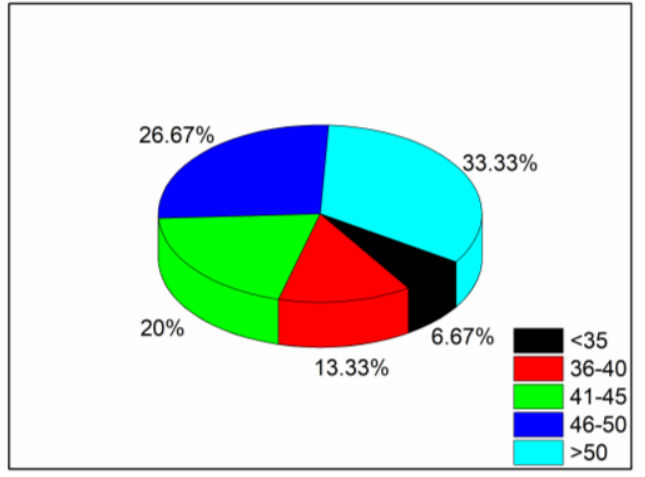

Gambar 1 Komposisi responden berdasarkan umur

Dari Gambar 1 komposisi responden berdasarkan umur memperlihatkan bahwa umur dominan responden pada penelitian ini adalah kisaran 41-45 tahun sebanyak 7 orang $(30,4 \%)$. Hal ini menunjukkan bahwa responden terdiri dari masyarakat yang telah memiliki pengalaman hidup yang cukup dan cukup matang dalam menentukan pilihan. b. Tingkat Pendidikan: komposisi responden berdasarkan tingkat pendidikan secara umum dapat dilihat pada Gambar 2.

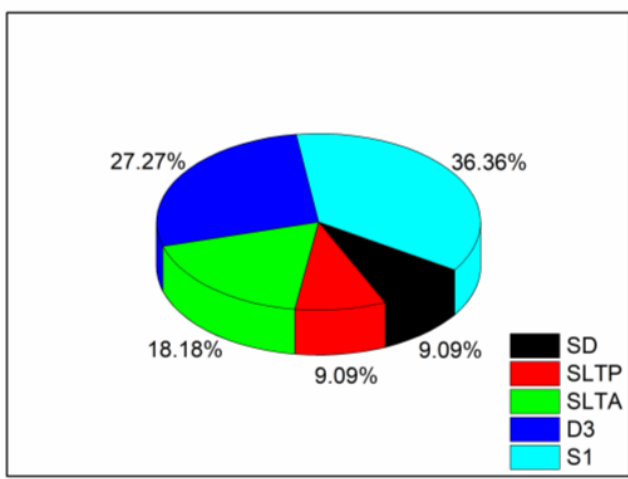

Gambar 2 Komposisi responden berdasarkan tingkat pendidikan

Berdasarkan Gambar 2. terlihat tingkat pendidikan responden paling dominan adalah Strata 1 (S1) sebanyak 11 orang $(47,83 \%)$. D3 sebanyak 9 orang $(39,13 \%)$, dan tamatan SLTA sebanyak 3 orang $(13,04 \%)$. Sedangkan tamatan SD dan SLTP tidak ada (0\%).

\section{HASIL DAN PEMBAHASAN}

Dari hasil kuisioner dan pengolahan data dengan SPSS Versi 13 dapat dilihat bagaimana penerapan SMK3 dalam penerapan program 
K3 di proyek konstruksi terdapat variabel X1 X10, disajikan pada Gambar 3.

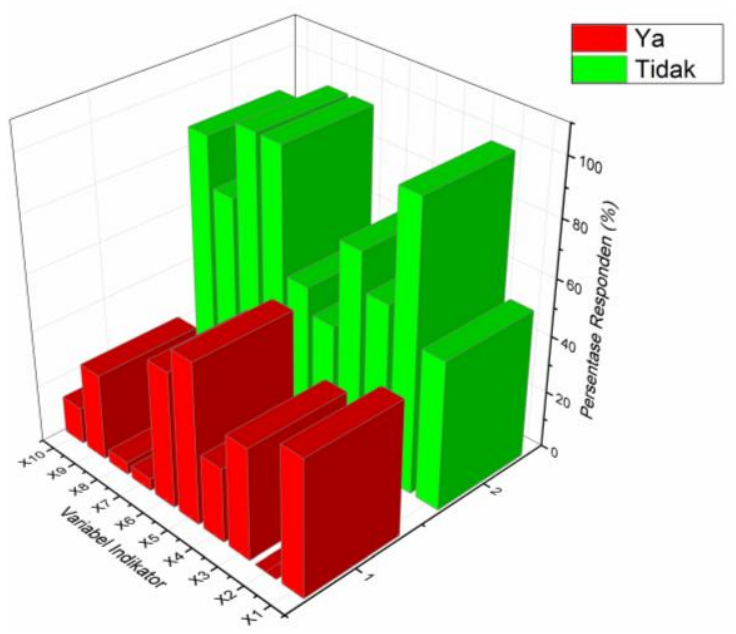

Gambar 3 Penerapan SMK3 dalam Program Kesehatan dan Keselamatan Kerja Variabel $\mathrm{X} 1-\mathrm{X} 10$

Gambar 3 merupakan hasil pengolahan data bagaimana penerapan SMK3 dalam penerapan Program K3. Hasil menununjukkan $26.93 \%$ responden yang telah melaksanakan K3 dan $73.07 \%$ responden menjawab belum melaksanakan K3 sesuai aturan. Hasil analisis data dapat diketahui bahwa proses penerapan K3 di Kota Payakumbuh termasuk Tingkat Penilaian Implementasi Kurang karena masih kurangnya kepedulian dan pengetahuan akan pentingnya K3. Padahal K3 adalah hal yang penting dalam keberhasilan sebuah proyek. Seharusnya penekanan terhadap K3 harus lebih di tegaskan walaupun tingkat proyek masih tergolong menengah kebawah karna kecelakaan bisa terjadi di mana saja dan kapan saja. Wahyuni (2016) mengatakan masih ada perusahaan yang belum menerapkan SMK3 sesuai peraturan perundang-undangan yang berlaku saat ini, masih ada beberapa perusahaan yang tidak menerapkan elemenelemen penting dalam kebijakan K3 perusahaan. Hal ini disebabkan tidak adanya keseriusan dari Direktur untuk menjalankan kebijakan K3 yang sudah mereka buat dan tidak adanya komunikasi dan sosialisasi kepada pihak-pihak yang terlibat pada proyek konstruksi yang mereka kerjakan. Perusahaan juga tidak menunjuk pekerja K3, ahli K3 di setiap proyek konstruksi yang mereka kerjakan sehingga K3 mereka abaikan. Dari penelitian ini, dalam penerapan SMK3 dikota
Payakumbuh tidak ada penetapan dan sasaran K3 yang dikonsultasikan dengan tenaga ahli, tujuan dan sasaran $\mathrm{K} 3$ yang ditetapkan tidak ditinjau secara teratur karena tidak adanya petugas K3 yang selalu meninjau lokasi kerja.

Berikutnya didapatkan hasil dengan variabel indikator X11-X19, bagaimana penerapan SMK3 dalam proses manajemen K3 (Kebijakan, Prosedur dan pelatihan) diperoleh $24,62 \%$ responden menyatakan telah melaksanakan SMK3 dan 75,38\% responden menyatakan belum melaksanakan SMK3 sesuai peraturan SMK3, disajikan pada Gambar 4.

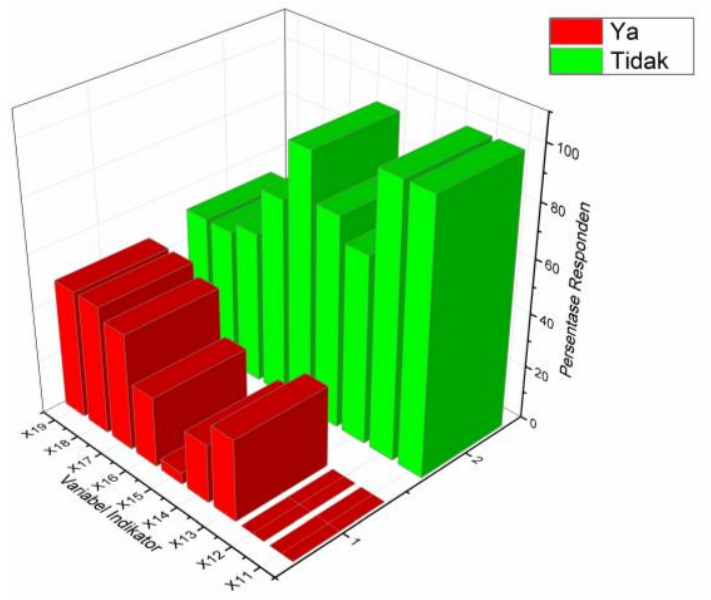

Gambar 4 Penerapan proses manajemen K3 (Kebijakan, Prosedur dan Pelatihan) X11-X19

Gambar 4 mengindikasikan bahwa pelaksana K3 di proyek termasuk Implementasi Kurang, hal ini disebabkan kurang memprioritaskan K3 seperti menempatkan organisasi $\mathrm{K} 3$ posisi yang dapat menentukan K3 dan belum mengkomunikasikan informasi K3 secara efektif. Apapun bentuknya kecelakaan K3 tetap akan di tanggung oleh pihak menajemen proyek dan akan mengeluarkan dana dispensasi yang sesuai dengan tingkat kecelakaan tyang terjadi, oleh sebab itu sudah sepatutnya pihak manajemen lebih mementingkan penerapan SMK3 di lapangan guna mengurangi tingkat kecelakaan kerja dan menghindari anggaran yang disebabkan oleh kecelakaan kerja. Para pekerjapun kurang menyadari akan pentingnya $\mathrm{K} 3$, dan menjadi tugas pihak manajemen untuk memberikan penjelasan mengenai K3 kepada para pekerja.

Hasil pengolahan data bagaimana penerapan ketersediaan Sumber daya K3 diperoleh $42,39 \%$ responden telah 
melaksanakan dan $57,61 \%$ responden belum menerapkan K3 dilapangan sesuai dengan peraturan, secara rinci disajikan pada Gambar 5.

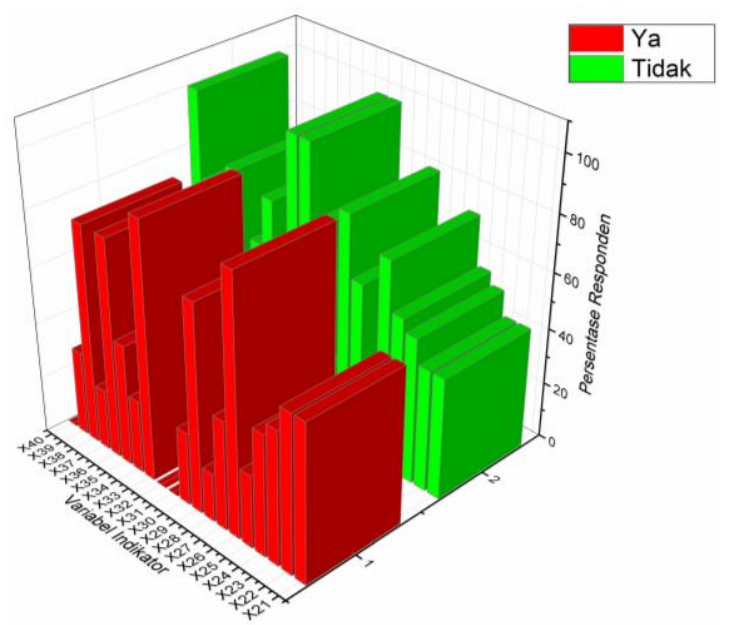

Gambar 5 Ketersediaan Sumber Daya K3

(Material, Peralatan, Pendanaan dan Staff K3) Indikator Variabel X21-X40

Gambar 5 menunjukkan bahwa di dalam proyek konstruksi pihak menajemen belum menempatkan sign board tentang K3 ataupun rambu peringatan bahaya secara baik di lapangan sehingga kesadaran tenaga kerja akan pentingnya $\mathrm{K} 3$ juga masih lemah yang kemungkinan besar tingkat kecelakaan akan terus meningkat. Perusahaan juga tidak menempatkan personil yang jelas dalam penanganan K3 di lapangan. Wahyuni 2016 dalam penelitiannya mengatakan keamanan bekerja berdasarkan SMK3 sudah banyak diterapkan oleh perusahaan yang diteliti, yaitu perusahaan jasa konstruksi di Sumatra Barat. Karena perusahaan tidak mau menanggung resiko yang lebih besar terhadap kecelakaan kerja. Alat Pelindung Diri (APD) disyaratkan bagi tenaga yang akan bekerja pada khususnya di lokasi pekerjaan yang punya potensial bahaya. Tetapi dalam pengawasan, masih ada perusahaan jasa konstruksi belum bisa melakukan sepenuhnya karena keterbatasan tenaga K3 untuk pengontrolan di lapangan, karena masih banyak tenaga yang tidak disiplin menggunakan alat pelindung diri, dan pengawas dari konsultan tidak dilibatkan dalam pengawasan $\mathrm{K} 3$ di proyek. Walaupun di lokasi proyek pihak menajemen telah menyediakan alat pelindung diri (APD) seperti helm,sepatu, kaca mata, belting, rompi K3, dll. Tetapi kebanyakan tenaga kerja kurang menyadari akan pentingnya K3 sehingga cendrung menolak untuk menggunakan APD tersebut. Karena kurangnya sosialisasi K3 sehingga para pekerja kurang memahaminya dan terkesan tidak peduli dengan $\mathrm{K} 3$ tersebut.

Masalah yang dihadapi perusahaan jasa kontraktor berdasarkan hasil penelitian disajikan pada Gambar 6.

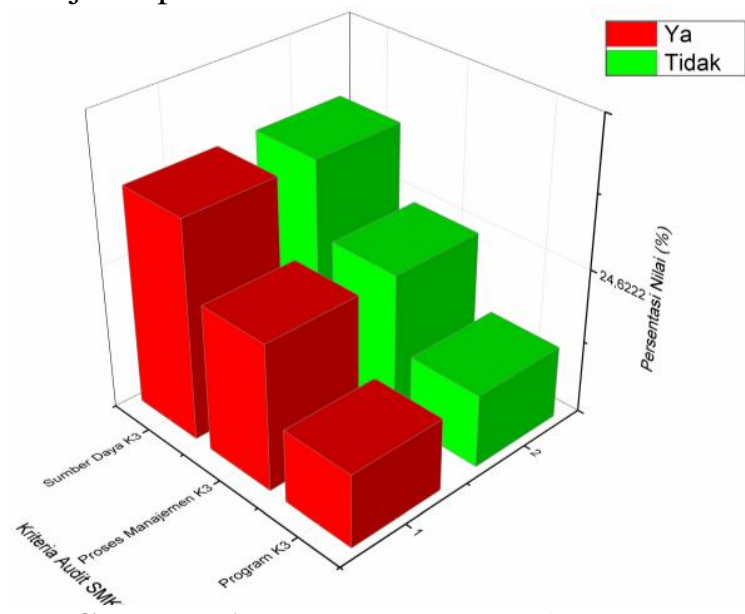

Gambar 6 Penerapan SMK3 di proyek

konstruksi Kota Payakumbuh berdasarkan kriteria audit

Berdasarkan analisis persentase pada Gambar 6, kriteria penerapan SMK3 pada perusahaan jasa kontruksi di Kota Payakumbuh yang belum dilaksanakan dengan baik adalah : (1) Program K3: dimana yang menjadi masalah dalam penerapan program $\mathrm{K} 3$ adalah tidak adanya penetapan dan sasaran $\mathrm{K} 3$ yang dikonsultasikan dengan tenaga ahli $\mathrm{K} 3$, adapun $\mathrm{K} 3$ yang diterapkan tidak ditinjau secara teratur dikarenakan tidak adanya petugas K3 yang selalu meninjau lokasi kerja. (2) Proses Manajemen K3: dalam penerapan proses manajemen $\mathrm{K} 3$ yang menjadi kendala dalam penerapannya adalah pelaksanaan pada proyek tidak memprioritaskan $\mathrm{K} 3$, perusahaan juga tidak menempatkan organisasi $\mathrm{K} 3$ di posisi yang dapat menentukan dan perusahaan tidak memiliki operasi standar pada setiap pelaksanaan proyek. (3) Sumber Daya K3: kendala yang dihadapi perusahaan dalam menerapkan ketersediaan sumber daya K3 diantaranya tidak adanya tersedia ramburambu peringatan tentang $\mathrm{K} 3$, terbatasnya anggaran yang dimiliki kontraktor dalam penerapan $\mathrm{K} 3$, dan juga karena tidak adanya personel yang jelas dalam penanganan K3 sehingga kelalaian dalam K3 masih sering dijumpai di lapangan, seperti pekerja yang tidak menggunakan helm dan sebagainya. Dari hasil penelitian ditemukan permasalahan yang menyebabkan penerapan Sistem Manajemen 
Kesehatan dan Keselamatan Kerja (SMK3) pada perusahaan Jasa Konstruksi di Kota Payakumbuh tidak diterapkan dengan baik, maka solusi yang bisa diberikan agar penerapan SMK3 dapat berjalan dengan baik, adalah : (1) Perusahaan hendaknya menyiapkan dana khusus untuk K3 agar penerapan K3 dapat terlaksana dengan baik. (2) Setiap pekerja seharusnya diberi pengarahan tentang $\mathrm{K} 3$ dan untuk dapat selalu menggunakan Alat Pelindung Diri dalam bekerja. (3) Menyediakan sumber daya K3 yang memadai dan memberikan pelatihan $\mathrm{K} 3$ kepada para pekerja. (4) Penekanan dari pihak pemerintah bisa membantu dalam meningkatkan K3. (5) Mensosialisasikan keuntungan dan kerugian apabila tidak menggunakan $\mathrm{K} 3$.

\section{PENUTUP}

Berdasarkan penelitian yang dilakukan didapatkan kesimpulan bahwa penerapan SMK3 pada perusahaan jasa konstruksi di Kota Payakumbuh berdasarkan hasil penelitian adalah $31,31 \%$ responden telah melaksanakan, $68,69 \%$ belum menerapkan SMK3. Menurut PP RI No. 50 tahun 2012, Implementasi SMK3 termasuk dalam tingkat penilaian kurang. Penerapan SMK3 oleh kontraktor di Kota Payakumbuh berdasarkan penelitian yang dilakukan masih perlu peningkatan dalam berbagai aspek. Hal ini dikarenakan kurangnya penerapan SMK3 yang dilaksanakan oleh kontraktor pada proyek konstruksi yang dijalankannya. Penulis menyarankan perlu adanya pengawasan yang lebih pada setiap perusahan jasa kontruksi, pekerja kontruksi dalam penerapan K3 disetiap pekerja kontruksi terutama di Kota Payakumbuh.

\section{UCAPAN TERIMAKASIH}

Ucapan terimakasih pada Yayasan Pendidikan Tinggi Payakumbuh atas dukungan terhadap penelitian ini. Terimakasih kepada Ramacos Fardela, M.Sc. telah membantu dalam penyajian data hasil penelitian.

\section{DAFTAR PUSTAKA}

Fitriana, L., \& Wahyuningsih, A. S. (2017). Penerapan Sistem Manajemen Keselamatan dan Kesehatan Kerja (SMK3) di PT. Ahmadaris. HIGEIA
(Journal of Public Health Research and Development), 1(1), 29-35.

Indrawati, A. D., Satrya, I. G. B. H., \& Dewi, S. K. S. (2017). Penerapan kesehatan dan keselamatan kerja: Pengaruhnya pada kepuasan kerja dan komitmen orgnisasional. Matrik: Jurnal Manajemen, Strategi Bisnis dan Kewirausahaan, 105115.

Koran Kompas diakses pada 4 Mei 2020 pada pukul 14.35 dengan judul: Indonesia Sudah Menjadi Negara Maju?, tersedia pada link: https://kompas.id/baca/riset/2020/03/30/in donesia-sudah-menjadi-negara-maju/

Permen PU, 2014, Peraturan Menteri Pekerjaan Umum Nomor: 05/PRT/M/2014 tentang Pedoman Sistem Manajemen Keselamatan dan Kesehatan Kerja (SMK3) Kontruksi Bidang Pekerjaan Umum, Jakarta.

Prabowo, A., Sudiajeng, L., \& Mudhina, M. M. (2020, January). Analisis Penerapan Sistem Manajemen Kesehatan Keselamatan Kerja (Smk3) Pada Proyek Reklamasi Apron Barat Bandar Udara I Gusti Ngurah Rai-Bali. In Proceedings (Vol. 1, No. 1, pp. 79-84).

Sanora, Well Of. (2012). Implementasi Kesehatan dan Keselamatan Kerja pada proyek Konstruksi Bangunan Milik Pemerintah di Kota Padang. Tesis Program Pascasarjana : Universitas Bung Hatta

Siahaan, T., Saleh, S. M., \& Rani, H. A. (2020). Penerapan Sistem Manajemen Keselamatan Dan Kesehatan Kerja (Smk3)(Studi Kasus Pada Proyek Preservasi Dan Pelebaran Jalan Kota Takengon-Sp. Uning-Uwaq). Jurnal Arsip Rekayasa Sipil dan Perencanaan, 3(1), 61-69.

Wahyuni, F.I. (2016). Implementasi Sistem Manajemen Kesehatan dan Keselamatan kerja (SMK3) pada perusahaan jasa Konstruksi di Wilayah Sumatera Barat. Tesis Progam Pascasarjana : Universitas Bung Hatta

Wahyuni, F. I. (2018). Penerapan Kesehatan dan Keselamatan Kerja (Smk3) (Studi Kasus pada Pembangunan Gedung Rawat Inap RSUD Dr. Achmad Mochtar Bukittinggi). Rang Teknik Journal, 1(1). 